\title{
COMPREHENSIVE META-ANALYTICAL SUMMARY ON HUMAN PAPILLOMAVIRUS ASSOCIATION WITH HEAD AND NECK CANCER
}

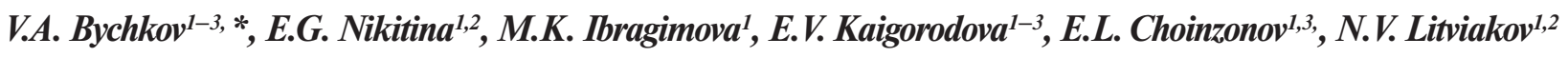 \\ ${ }^{1}$ Tomsk Cancer Research Institute, Tomsk 634050, Russian Federation \\ ${ }^{2}$ National Research Tomsk State University, Tomsk 634050, Russian Federation \\ ${ }^{3}$ Siberian State Medical University, Tomsk 634050, Russian Federation
}

An etiological role of high risk human papillomavirus (HPV) in the development of cervical cancer has been well established. Hence, attention of researchers has been focused on the role of HPV in pathogenesis of other malignancies, such as head and neck cancers. An analysis of epidemiological data on the prevalence of HPV infection among healthy people and patients with precancerous lesions and/or cancer is an important step in understanding the role of HPV in head and neck carcinogenesis. More and more data demonstrate the impact of HPV infection on disease outcome. HPV-positive patients have been shown to have better responses to radiotherapy and better overall and disease-free survival than HPV-negative patients. This review presents data of the metaanalysis based on a large number of original studies on HPV prevalence in patients with precancerous lesions and in patients with oral, oropharyngeal and laryngeal cancers as well as findings on the impact of HPV infection on survival of these patients.

Key Words: meta-analysis, human papillomavirus, head and neck cancer, survival.

Members of the Papillomaviridae family play an important role in the development of certain types of human malignancies, such as oropharyngeal and anogenital cancers [1, 2]. Head and neck cancer (HNC) is the fifth most common type of cancer and the sixth most common cause of cancer death worldwide. About 550,000 new cases are reported worldwide annually [3] .

The HPV involvement in oral and oropharyngeal carcinogenesis was suggested based on viral tropism to the epithelial cells and oncogenic potential of high risk HPV genotypes in the pathogenesis of anogenital neoplasia, particularly in cervical squamous cell carcinoma and the morphological similarities between oropharyngeal and genital epithelia [4-9].

Almost $90 \%$ of HNC cases are of squamous epithelial cell origin that could be characterized by a multistep and multifactorial pathogenesis [10-12]. It has been shown that besides smoking and alcohol use, some infectious pathogens, such as human papillomavirus (HPV) may act as a carcinogenic factor for HNC of certain locations, particularly the oropharynx $[13,14]$.

To evaluate the etiological role of HPV, it is important to understand whether the prevalence of HPV DNA become higher during malignant transformation of normal epithelium to dysplasia, then to carcinoma in situ and finally to invasive cancer. A large amount of the data giving evidence of HPV DNA in head and neck squamous cell carcinoma (HNSCC) has been accumulated and a systematic review and meta-analyses of these data should be performed. Since most of the original studies were conducted using small number of samples, the meta-analysis is an effective statistical tool, which depends less on specific initial data than

Submitted: August 08, 2015.

*Correspondence: E-mail: virology@oncology.tomsk.ru Abbreviation used: DFS - disease-free survival; HNC - head and neck cancer; HNSCC - head and neck squamous cell carcinoma; HPV - human papillomavirus; HR - hazard ratio; OOPD - oral cavity and oropharyngeal dysplasia; $\mathrm{OR}$ - odds ratio; OS - overall survival. on each study individually, thus solving the problem of low statistical power of each individual study.

It should be noted that each meta-analysis determines its own inclusion criteria; therefore, the following results of evaluation are rather complementary than contradictory and allow the studied problem to be described more adequately. The meta-analyses, described in the present article are mainly focused on the following points:

- prevalence of HPV in HNSCC tissues, which is expressed as a percentage, usually with 95\% confidence interval $(\mathrm{Cl})$;

- the odds ratio (OR) - the ratio of the probability of presence the studied risk factors in the HPVpositive patients compared with HPV-negative ones;

- survival of HPV-positive patients. Typically, the survival rate is estimated, using the Kaplan - Meier analysis and it is quantitatively assessed as a percentage survival of each group or calculated risk ratio of adverse outcome (hazard ratio - HR) in the presence of HPV-infection. The lower HR value, the difference in survival between HPV-positive and HPV-negative patients is higher.

The main aim of this review was to summarize all certain segments of available information with the focus on infection prevalence, risk of HPV-associated $\mathrm{HNC}$, and also progression and survival of viruspositive and virus-negative individuals.

The prevalence of HPV in head and neck precancerous lesions. There are two types of precancerous lesions in the oral cavity mucosa: leukoplakia and erythroplakia [15]. Based on published data [2], the incidence of HPV DNA in leukoplakia was 31.1\% (300/964 cases). The predominant HPV types were HPV-6 and HPV-11 (HPV-6/-11, 55.8\%) followed by HPV-16/-18 (28.2\%). Only a few cases of erythroplakia have been described in the literature. The authors reported on 32 cases of erythroplakia, 9 of them had HPV-16 DNA. In addition, Nielsen et al. [16] de- 
scribed 10 cases with erythroplakia, $50 \%$ of them being HPV-positive. The prevalence of HPV-16/-18 in oral cavity and oropharyngeal dysplasia (OOPD) has been recently shown [17].

The meta-analysis was performed using the results of 22 studies that reported prevalence of HPV-16 and/or -18 in 458 OOPD cases. The overall prevalence of HPV$16 /-18$ in OOPD lesions was $24.5 \%$ (95\% Cl 16.4-36.7). The individual prevalence for HPV- 16 alone was $24.4 \%$. The prevalence of HPV-16/-18 in oral cavity lesions was $25.3 \%$ (95\% Cl 14.2-45.2). The odds of HPV$16 /-18$ detection in dysplastic lesions in males were twice that of females (OR 2.44). HPV-16/-18 were 3 -fold more frequent in dysplastic lesions (OR 3.29; 95\% Cl 1.95-5.53) and invasive cancers (OR 3.43; $95 \% \mathrm{Cl} 2.07-5.69$ ), than in normal tissue samples. There were no significant differences in the incidence of HPV-16/-18 between patients with mild, moderate and severe dysplastic changes.

Results of the presented meta-analysis supportan assumption that the HPV-16/-18 accumulation occurs in the early stage of oral and oropharyngeal carcinogenesis.

The prevalence of HPV in HNSCC. The high HPV prevalence in HNSCC explains the abundance of the reviews with the scope on a particular problem. Most of the studies took into account the specific anatomic sites and just very few of them has described HPV prevalence in HNSCC. The average of HPV prevalence in HNSCC was 21.9\% [20], 25.9\% [18], 34.5\% [19], which is described in 3 meta-analyses performed on a cohort of about 5000 patients (Table 1).

Interestingly, the difference in HPV DNA prevalence is observed between the cohorts with similar percentage of patients. It is likely to be caused by different inclusion criteria used in studies described above. Furthermore, the following points can also have a considerable effect: variety of methods used for HPV detection, different origin of patients, varying percentage of cases with particular cancer sites. Thus, there is a definite requisite for stratification of $\mathrm{HNC}$ patient groups depending on the anatomical site of squamous cell carcinoma.

It was shown that HPV-16 is the most prevalent genotype among all HNSCCs (73.3\% [18], 86.7\% [20], $82.5 \%$ [21]), followed by HPV-18 and -33 [18, 20]. Hobbs et al. [22] in a meta-analysis based on 17 studies with the total of 2012 patients, showed that HPV is most strongly associated with tonsillar cancer (OR 15.1; 95\% $\mathrm{Cl}$ 6.8-33.7), is intermediate for oropharyngeal cancer (OR 4.3; 95\% Cl 2.1-8.9), and is the weakest for oral cancer (OR 2.0; 95\% Cl 1.0-4.2).

It was also shown that HPV status was associated with p16 expression (adjusted OR 3.00; 95\% $\mathrm{Cl} 0.90-9.70 ; p=0.18$ ), and HPV-positive tumors were less likely to harbor p53 mutations (adjusted OR 0.21; 95\% Cl 0.04-0.38; $p=0.015$ ) [20].

Survival rate of patients with HPV-positive and HPV-negative HNSCC cases was studied in three meta-analyses, and it was shown that HPV-positive patients had better prognosis: HR for overall survival (OS) was 0.42 [20], 0.46 [23], and 0.85 [24], and
HR for disease-free survival (DFS) was 0.41 [23] and 0.62 [24] (Table 2).

Table 1. HPV prevalence by different sites of HNC

\begin{tabular}{|c|c|c|c|c|}
\hline State & $\begin{array}{c}\text { HPV prevalence } \\
(95 \% \mathrm{CI}), \%\end{array}$ & Study type & $\mathrm{N}$ & Source \\
\hline Leukoplakia & $\begin{array}{l}\text { HPV-6/-11-55.8\% } \\
\text { HPV-16/-18 - } 28.2 \%\end{array}$ & Review & 364 & [2] \\
\hline Erythroplakia & HPV $-16-28.1 \%$ & & 32 & \\
\hline & HPV $-50.0 \%$ & Original study & 10 & [16] \\
\hline Dysplasia & $\begin{array}{l}\text { HPV-16/-18 - 24.5\% } \\
(16.4-36.7)\end{array}$ & $\begin{array}{l}\text { Meta-analysis } \\
\text { of } 22 \text { studies }\end{array}$ & 458 & [17] \\
\hline \multirow[t]{6}{*}{ HNC } & $\begin{array}{l}\text { Pooled HPV }-25.9 \% \\
(24.7-27.2)\end{array}$ & $\begin{array}{l}\text { Meta-analysis } \\
\text { of } 60 \text { studies }\end{array}$ & 5046 & [18] \\
\hline & $\begin{array}{l}\text { Pooled HPV }-34.5 \% \\
(28.4-40.6)\end{array}$ & $\begin{array}{l}\text { Meta-analysis } \\
\text { of } 62 \text { studies }\end{array}$ & 4852 & [19] \\
\hline & $\begin{array}{l}\text { Pooled HPV }-21.9 \% \\
(21.0-23.0)\end{array}$ & $\begin{array}{l}\text { Meta-analysis } \\
\text { of } 34 \text { studies }\end{array}$ & 5681 & [20] \\
\hline & $\begin{array}{l}\text { HPV- } 16-86.7 \% \\
(85.0-89.0)\end{array}$ & $\begin{array}{l}\text { Meta-analysis } \\
\text { of } 34 \text { studies }\end{array}$ & 5681 & [20] \\
\hline & HPV- $16-82.4 \%$ & $\begin{array}{l}\text { Meta-analysis } \\
\text { of } 269 \text { studies }\end{array}$ & 13972 & [21] \\
\hline & HPV- $16-73.3 \%$ & $\begin{array}{l}\text { Meta-analysis } \\
\text { of } 60 \text { studies }\end{array}$ & 5046 & [18] \\
\hline \multirow[t]{3}{*}{ Oral cancer } & $\begin{array}{l}\text { Pooled HPV }-23.5 \% \\
(21.9-25.1)\end{array}$ & $\begin{array}{l}\text { Meta-analysis } \\
\text { of } 35 \text { studies }\end{array}$ & 2642 & [18] \\
\hline & $\begin{array}{l}\text { Pooled HPV }-38.1 \% \\
(30.0-46.2)\end{array}$ & $\begin{array}{l}\text { Meta-analysis } \\
\text { of } 47 \text { studies }\end{array}$ & 3238 & [19] \\
\hline & HPV- $16-68.2 \%$ & $\begin{array}{l}\text { Meta-analysis } \\
\text { of } 35 \text { studies }\end{array}$ & 2642 & [18] \\
\hline \multirow[t]{5}{*}{$\begin{array}{l}\text { Oropharyn- } \\
\text { geal cancer }\end{array}$} & $\begin{array}{l}\text { Pooled HPV }-35.6 \% \\
(32.6-38.7)\end{array}$ & $\begin{array}{l}\text { Meta-analysis } \\
\text { of } 27 \text { studies }\end{array}$ & 969 & [18] \\
\hline & $\begin{array}{l}\text { Pooled HPV }-47.7 \% \\
(42.9-52.3)\end{array}$ & $\begin{array}{l}\text { Meta-analysis } \\
\text { of } 269 \text { studies }\end{array}$ & 5396 & [21] \\
\hline & Pooled HPV - $63.8 \%$ & Original study & 323 & [28] \\
\hline & HPV- $16-86.7 \%$ & $\begin{array}{l}\text { Meta-analysis } \\
\text { of } 27 \text { studies }\end{array}$ & 969 & [18] \\
\hline & HPV-16-96.1\% & Original study & 323 & [28] \\
\hline \multirow[t]{4}{*}{$\begin{array}{l}\text { Laryngeal } \\
\text { cancer }\end{array}$} & $\begin{array}{l}\text { Pooled HPV }-24.0 \% \\
(21.8-26.3)\end{array}$ & $\begin{array}{l}\text { Meta-analysis } \\
\text { of } 35 \text { studies }\end{array}$ & 1435 & {$[18]$} \\
\hline & $\begin{array}{l}\text { Pooled HPV }-28.0 \% \\
(23.5-32.9)\end{array}$ & $\begin{array}{l}\text { Meta-analysis } \\
\text { of } 55 \text { studies }\end{array}$ & 2559 & [34] \\
\hline & HPV- $16-69.2 \%$ & $\begin{array}{l}\text { Meta-analysis } \\
\text { of } 35 \text { studies }\end{array}$ & 1435 & [18] \\
\hline & $\begin{array}{l}\text { HPV }-16-19.8 \% \\
(15.7-24.6)\end{array}$ & $\begin{array}{l}\text { Meta-analysis } \\
\text { of } 55 \text { studies }\end{array}$ & 2559 & [34] \\
\hline
\end{tabular}

The prevalence of HPV in oral cancer. Several meta-analyzes demonstrated the prevalence of HPV in the oral cancer $[18,19,23]$. According to these data, the HPV prevalence in oral cancer was approximately the same as in other HNC sites (23.5\%). Other data demonstrate much higher prevalence ( $38.1 \%$ of cases). HPV- 16 was detected in $68.2 \%$ and HPV-18 in $34.1 \%$ (see Table 1).

The pooled HR for oral cancer was 0.32 (95\% CI 0.16-0.68), that is mean, the OS rate in HPV-positive patients was 3 times higher than in HPV-negative ones (see Table 2).

The prevalence of HPV in oropharyngeal cancer. An independent population-based study in the United States $(n=271)$ showed that the populationlevel incidence of HPV-positive oropharyngeal cancers increased by $225 \%$ from 1984 to 2004 (from 0.8 per 100,000 to 2.6 per 100,000 ), and incidence for HPVnegative cancers declined by $50 \%$ [25]. It is estimated that by 2020 , the annual number of HPV-positive oropharyngeal cancers will exceed the annual number of cervical cancers. 
In the meta-analysis of Kreimer et al. [18], the frequency of HPV detection was significantly higher in oropharyngeal cancer (35.6\% of 969 cases) compared to oral cancer (23.5\% of 2642 cases) and laryngeal cancer (24.0\% of 1435 cases). HPV-16 was detected in $86.7 \%$ of patients with oropharyngeal cancer and HPV-18 in $2.8 \%$ of patients (see Table 1 ).

Table 2. Impact of HPV-infection on survival rate of HNC patients

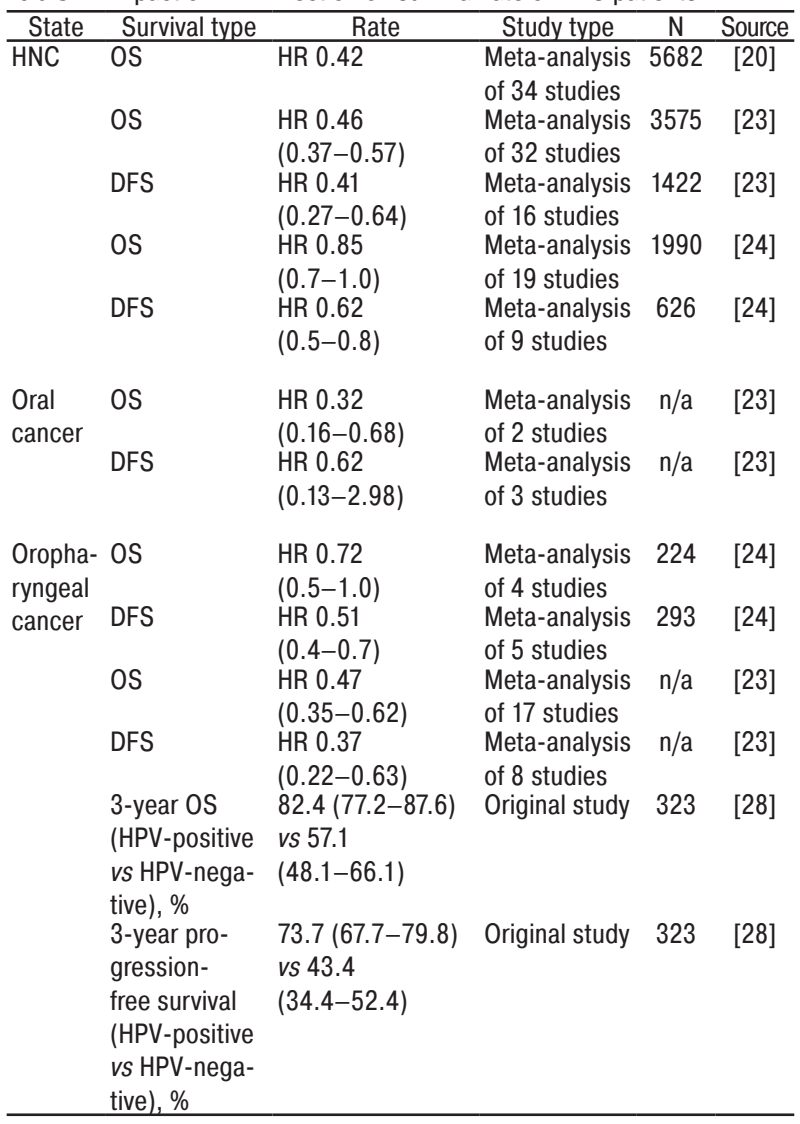

n/a - not available.

A meta-analysis of Mehanna et al. [21] based on 269 studies (1970-2008) included 5396 patients with oropharyngeal cancer and 13,972 patients with non-oropharyngeal cancer. The overall pooled HPV prevalence in patients with oropharyngeal cancer was 47.7\% (95\% Cl 42.9-52.5). Overall HPV prevalence in oropharyngeal cancer increased significantly over time in Europe $(p<0.004)$ and in North America $(p<$ $0.002)$ from $40.5 \%(95 \% \mathrm{Cl} 35.1-46.1)$ in the 54 studies that recruited patients before 2000 to $64.3 \%$ (95\% Cl 56.7-71.3) in cohorts recruited between 2000 and 2004 (22 studies) and to $72.2 \%$ (95\% Cl 52.9-85.7) from 2004-2008 (4 studies) (see Table 1). These findings were consistent with the data obtained by Chaturvedi et al. [25]. Overall HPV prevalence differed by geographic region. The overall prevalence was 35.3\% in Europe, 50.7\% in North America and 32.2\% in all other regions $(p=0.008)$. For oropharyngeal cancer, HPV-16 was positive in 1353 (95.7\%) of 1414 cases.

Overall HPV prevalence in non-oropharyngeal cancer was $21.8 \%$ (95\% Cl 18.9-25.1), and there appeared to be statistically insignificant, declining trend over time. Thus, the pooled HPV prevalence was $22.2 \%$ before 2000 (95\% Cl 18.4-26.4), compared with 17.2\%
(95\% Cl 11.9-24.4) between 2000 and 2004 and 6.1\% (95\% Cl 0.7-39) from 2004 to 2008 . No statistically significant difference between the regions was found. The HPV-16 was detected in 1626 (73.9\%) out of the 2199 HPV-positive patients with oropharyngeal cancer.

Gillison et al. [26] reported that the major risk factors for HPV-positive oropharyngeal cancer are: high lifetime number of both oral and vaginal sexual partners, early age of sexual debut, anogenital warts and the consumption of marijuana. HPV-negative oropharyngeal cancer is strongly associated with tobacco and alcohol consumption, older age and poor oral hygiene.

According to a meta-analysis of Ragin et al. [24], HPV-positive patients with oropharyngeal cancer had a $28 \%$ lower risk of dying compared with HPV-negative patients (HR 0.72; 95\% CI 0.5-1.0) (see Table 2). Similar findings were published in a prospective analysis of data from clinical trials [27]. In order to evaluate other favorable prognostic factors associated with HPV status of the tumor, Ang et al. [28] analyzed survival rates of patients with oropharyngeal squamous cell carcinoma. A total of $63.8 \%$ of patients with oropharyngeal cancer (206 of 323) had HPV-positive tumors, and 198 (96.1\%) of 206 were positive for HPV-16. Kaplan - Meier analysis revealed that HPV-positive cancer patients had better overall and DFS compared with HPV-negative patients $(p<0.001)$. 3-year OS was $82.4 \%(95 \%$ Cl 77.2-87.6) in HPV-positive patients and 57.1\% (95\% Cl 48.1-66.1) in HPV-negative patients. The 3-year DFS rates were $73.7 \%(95 \% \mathrm{Cl} 67.7-79.8)$ and $43.4 \%$ (95\% Cl 34.4-52.4), respectively.

In the multivariable analysis, the age, race, performance status, tumor stage, nodal stage, and number of pack-years of tobacco smoking were also significant determinants of the OS and DFS.

Tumors were evaluated for the expression of not only HPV, but also for p16, a known biomarker of HPV infection. The presence of HPV and $\mathrm{p} 16$ expression in tumors were in good agreement $(\mathrm{K}=0.80 ; 95 \% \mathrm{Cl} 0.73-0.87$ ). Using p16 expression as a stratification factor, the differences in the OS and DFS rates, that were consistent with those based on HPV status, were shown. Thus, the 3-year survival rate was $83.6 \%$ in patients with p16positive expression and $51.3 \%(95 \% \mathrm{Cl} 41.5-61.0)$ in the patients with p16-negative expression.

Recursive-partitioning analysis showed that the HPV status of the tumor was the major determinant of OS, followed by the number of pack-years of tobacco smoking and then nodal stage for HPV-positive tumors, or tumor stage for HPV-negative tumors.

In a meta-analysis by O'Rorke et al. [23], the authors examined the difference in OS between the HPVpositive and HPV-negative patients with oropharyngeal cancer and found that the pooled HR was 0.47 (95\% Cl 0.35-0.62) (see Table 2).

The prevalence of HPVin laryngeal cancer. In a meta-analysis stratified by anatomical site, Kreimer et al. [18] reported that the prevalence of HPV in laryngeal squamous cell carcinomas was $24.0 \%$ (of a total of 1435 cases) and found HPV-16 positivity in $69.2 \%$ of cases and HPV- 
18 positivity in $17.0 \%$ of cases. Meta-analysis by Torrente et al. [29] demonstrated the same HPV prevalence (24.0\%; 95\% $\mathrm{Cl} 21.8-26.3)$ in laryngeal cancer patients. The authors paid attention to the fact that the overall HPV prevalence in normal laryngeal mucosa was not determined because sampling methods for HPV detection in healthy cells were not standardized, and prevalence estimates remained inconsistent.

The reported incidence of HPV infection in normal laryngeal mucosa has been as high as $19.0 \%$ [30-33] . These results suggest that the number of HPV-positive cancers observed might reflect the prevalence of latent HPV infections in the vocal cord epithelium.

Li et al. [34] performed a systemic review and metaanalysis based on 55 studies that tested the presence of HPV in laryngeal cancer patients. It was reported that HPV DNA was detected in $28.0 \%$ of the 2559 cases of laryngeal carcinoma (95\% Cl $23.5-32.9 \%$ ) (see Table 1). The prevalence of high risk HPV types was significantly higher than that of low risk HPV types (26.6\% vs $3.7 \%$ ). The most common HPV type was HPV-16, with a summary prevalence of $19.8 \%$ (95\% Cl 15.7-24.6). The remaining most frequently identified HPV types were HPV-18 $(6.2 \%$ of cases; 95\% Cl 4.0-9.5), HPV-33 (3.3\%; 95\% Cl 2.1-5.1), HPV-31 (2.4\%; 95\% Cl 1.3-4.4), HPV-6 (4.3\%; 95\% $\mathrm{Cl}$ 2.4-7.7) and HPV-11 (2.3\%; 95\% Cl 1.2-4.4).

Analyses stratified by cancer location showed that laryngeal cancers in the glottis region had the highest HPV prevalence (35.2\%; 95\% Cl 28.2-42.8), followed by those in the supraglottic region $(30.5 \%$; $95 \% \mathrm{Cl} 24.0-37.8)$ and the subglottic region (27.5\%; $95 \% \mathrm{Cl} 17.5-40.4)$. The microenvironment of the glottis might favor HPV infection, because the squamocolumnar junction in the ventricle is similar to the cervical transformation zone.

The estimated HPV prevalence among laryngeal cancers might vary with respect to the analyzed population, HPV detection methods and tumor characteristics. The prevalence of high risk HPV was found to be much higher than that of low risk HPV types.

Various HPV prevalences in laryngeal cancers were observed in different geographical regions (range; 25.6-35.6\%). Studies from South America reported a higher rate of HPV infection compared with that observed in Asia, North America and Europe.

In a meta-analysis based on 12 case-control studies, Li etal. [34] estimated the association between HPV infection and the risk of laryngeal cancer. A total of 638 patients with laryngeal cancer and 419 controls were enrolled. It was shown that HPV infection significantly increased the risk of laryngeal cancer (OR 5.39; 95\% Cl 3.25-8.94), this OR was higher than that for oropharyngeal cancer (OR 4.3; 95\% Cl 2.1-8.9) and oral cancer (OR 2.0; 95\% Cl 1.2-3.4) demonstrated by Hobbs et al. [22].

The OR of individual types indicated differences in the magnitudes of the association for HPV16 (6.07; 95\% Cl 3.44-10.7) and HPV-18 (4.16; 95\% $\mathrm{Cl} 1.87-20.04)$. For low risk HPV ( 16 and 11 types) the OR were not statistically significant.
When estimating survival, O'Rorke et al. [23] showed that patients with HPV-positive laryngeal squamous cell carcinoma had a $50 \%$ lower risk of mortality compared to HPV-negative patients (HR 0.5; 95\% Cl 0.33-0.77) (see Table 2).

\section{CONCLUSION}

The prevalence of HPV was found to be greater in HNC than in dysplasia and HPV virus was most frequently detected in oropharyngeal cancer among the different anatomical sites, HPV-16 was the most prevalent HPV type in HNC.

In spite of tumor location, the risk of dying was lower and survival was higher in HPV-positive patients than in HPV-negative patients, indicating that along with the carcinogenic effect, HPV is able to modulate the disease and influence on the prognosis.

\section{ACKNOWLEDGMENT}

This research is supported by Tomsk State University Competitiveness Improvement Program.

The study was conducted with financial support from the Council for Grants of the President of the Russian Federation for the state support of young philosophy doctors, agreements of SC № 14.120.14.168-MD.

\section{REFERENCES}

1. Zur Hausen H. Papillomaviruses in human cancer. Appl Pathol 1987; 5: 19-24.

2. Syrjanen S. Human papillomavirus (HPV) in head and neck cancer. J Clin Virol 2005; 32S: S59-66.

3. Jemal A, Bray F, Center MM, et al. Global cancer statistics. CA Cancer J Clin 2011; 61: 69-90.

4. Syrjanen K, Syrjanen S, Lamberg M, et al. Morphological and immunohistochemical evidence suggesting human papillomavirus (HPV) involvement in oral squamous cell carcinogenesis. Int J Oral Surg 1983; 12: 418-24.

5. Zur Hausen H. Papillomavirus infections - a major cause of human cancers. Biochim Biophys Acta 1996; 1288: F55-F78.

6. Zur Hausen H. Papillomavirus and cancer: from basic studies to clinical application. Nat Rev Cancer 2002; 2: 342-50.

7. Erdmann J. Recent studies attempt to clarify relationship between oral cancer and human papillomavirus. J Natl Cancer Inst 2003; 95: 638-9.

8. Nair S, Pillai M. Human papillomavirus and disease mechanisms: relevance to oral and cervical cancers. Oral Dis 2005; 11: 350-9.

9. Thompson IO, Van Der Bijl P, Van Wyk CW, et al. A comparative lightmicroscopic, electron-microscopic and chemical study of human vaginal and buccal epithelium. Arch Oral Biol 2001; 46: 1091-8.

10. Franceschi S, Levi F, La Vecchia C. Comparison of the effect of smoking and alcohol drinking between oral and pharyngeal cancer. Int J Cancer 1999; 83: 1-4.

11. Scully C, Field JK, Tanzawa H. Genetic aberrations in oral or head and neck squamous cell carcinoma (SCCHN): 1. Carcinogen metabolism, DNA repair and cell cycle control. Oral Oncol 2000; 36: 256-63.

12. Girja KP, Sundharam BS, Krishnan PA, et al. Biochemical changes of saliva in tobacco chewers tobacco smokers, alcohol consumers, leukoplakia and oral cancer patients. Indian J Dent Res 2002; 13: 102-7.

13. Lutzky VP, Moss DJ, Chin D, et al. Biomarkers for cancers of the head and neck. Clinical Medicine: Ear, Nose and Throat 2008; 1: 5-15. 
14. Duray A, Descamps G, Arafa M, et al. High incidence of high-risk HPV in benign and malignant lesions of the larynx. Int J Oncol 201; 39: 51-9.

15. Axell T, Pindborg JJ, Smith CJ, et al. Oral white lesions with special reference to precancerous and tobaccorelated lesions: conclusions of an international symposium held in Uppsala, Sweden, May 18-21, 1994. J Oral Pathol Med 1996; 25: 49-54.

16. Nielsen $H$, Norrild B, Vedtofte $P$, et al. Human papillomavirus in oral premalignant lesions. Eur J Cancer Part B: Oral Oncol 1996; 32: 264-70.

17. Jayaprakash V, Reid M, Hatton E, et al. Human papillomavirus types 16 and 18 in epithelial dysplasia of oral cavity and oropharynx: a meta-analysis, 1985-2010. Oral Oncol 2011; 47: 1048-54.

18. Kreimer AR, Clifford GM, Boyle P, et al. Human papillomavirus types in head and neck squamous cell carcinomas worldwide: a systematic review. Cancer Epidemiol Biomarkers Prev 2005; 14: 467-75.

19. Termine N, Panzarella V, Falaschini S, et al. HPV in oral squamous cell carcinoma $v s$ head and neck squamous cell carcinoma biopsies: a meta-analysis (1988-2007). Ann Oncol 2008; 19: 1681-90.

20. Dayyani F, Etzel CJ, Liu M, et al. Meta-analysis of the impact of human papillomavirus (HPV) on cancer risk and overall survival in head and neck squamous cell carcinomas (HNSCC). Head Neck Oncol 2010; 29: 2-15.

21. Mehanna H, Beech T, Nicholson T, et al. Prevalence of human papillomavirus in oropharyngeal and nonoropharyngeal head and neck cancer - systematic review and meta-analysis of trends by time and region. Head Neck 2013; 35: 747-55.

22. Hobbs CG, Sterne JA, Bailey M, et al. Human papillomavirus and head and neck cancer: a systematic review and meta-analysis. Clin Otolaryngol 2006; 31: 259-66.

23. O'Rorke MA, Ellison MV, Murray LJ, et al. Human papillomavirus related head and neck cancer survival: a systematic review and meta-analysis. Oral Oncol 2012; 48: 1191-201.
24. Ragin CCR, Taioli E. Survival of squamous cell carcinoma of the head and neck in relation to human papillomavirus infection: review and meta-analysis. Int $\mathrm{J}$ Cancer 2007; 121: 1813-20.

25. Chaturvedi AK, Engels EA, Pfeiffer RM, et al. Human papillomavirus and rising oropharyngeal cancer incidence in the United States. J Clin Oncol 2011; 29: 4294-301.

26. Gillison ML, Zhang Q, Jordan R, et al. Tobacco smoking and increased risk of death and progression for patients with p16-positive and p16-negative oropharyngeal cancer. J Clin Oncol 2012; 30: 2102-11.

27. Fakhry C, Westra WH, Li S, et al. Improved survival of patients with human papillomavirus-positive head and neck squamous cell carcinoma in a prospective clinical trial. J Natl Cancer Inst 2008; 100: 261-9.

28. Ang KK, Harris J, Wheeler R, et al. Human papillomavirus and survival of patients with oropharyngeal cancer. N Engl J Med 2010; 363: 24-35.

29. Torrente MC, Rodrigo JP, Haigentz M, et al. Human papillomavirus infections in laryngeal cancer. Head Neck 2011; 33: 581-6.

30. Fukushima K, Ogura H, Watanabe $S$, et al. Human papillomavirus type 16 DNA detected by the polymerase chain reaction in non-cancer tissues of the head and neck. Eur Arch Otorhinolaryngol 1994; 251: 109-12.

31. Rihkanen H, Peltomaa J, Syrjanen S. Prevalence of human papillomavirus (HPV) DNA in vocal cords without laryngeal papillomas. Acta Otolaryngol 1994; 114: 348-51.

32. Garcia-Milian R, Hernandez H, Panade L, et al. Detection and typing of human papillomavirus DNA in benign and malignant tumours of laryngeal epithelium. Acta Otolaryngol 1998; 118: 754-8.

33. Smith EM, Summersgill KF, Allen J, et al. Human papillomavirus and risk of laryngeal cancer. Ann Otol Rhinol Laryngol 2000; 109: 1069-76.

34. Li X, Gao L, Li H, et al. Human papillomavirus infection and laryngeal cancer risk: a systematic review and meta-analysis. J Infect Dis 2013; 207: 479-88. 